\title{
Stoichiometry of Protein Interactions in Bacteriophage Tail Assembly
}

\author{
Fumio Arisaka \\ Tokyo Institute of Technology, Graduate School of Bioscience and Biotechnology \\ Department of Life Science \\ Japan
}

\section{Introduction}

The concept of self-assembly of supramolecules from subunit proteins originated from the study of tobacco mosaic virus, TMV, by Fraenkel-Conrat \& Williams in 1955 . They succeeded in reassembly of viable TMV from the isolated coat protein and detergentextracted RNA. Since then, disassembly and reassembly or self-assembly have been investigated in various systems including simple plant viruses and bacteriophages. Disassembly and reassembly, however, was only successful for simple single-stranded RNA viruses and phage, and have never been successful for other phages including singlestranded DNA phage such as phiX174. The reason is that in the case of bacteriophages even such simple phage has so-called scaffolding proteins which are not present in the mature phage. Larger and more complicated phage such as phage T4 has virion proteins which undergo "processing" or cleavage at the N-terminal region during assembly. Also, most of the virion has extremely stable capsid which can be dissociated only under denaturing conditions. Thus, phage assembly has been studied using "assembly-naïve" proteins (King, 1968). "Assembly naïve" means that the proteins have never experienced assembly. In in vitro complementation, "assembly-naive" proteins in the lysates of mutant phage-infected cells were mixed to let them assemble to form viable virions. Overexpression system can be used to produce "assembly-naive" proteins in place of the phage-infected lysate. Constituent subunit proteins of supramolecules including viruses, muscle myosin/actin, bacterial flagella etc. or oligomeric proteins have the intrinsic properties to assemble spontaneously.

Bacteriophage or phage is a virus that infects bacterium. Bacteriophage has some distinct features as compared with animal or plant viruses. First, they all inject DNA into the host cell leaving the protein capsids outside. Secondly, more than $95 \%$ of bacteriophage have tails (Ackerman, 2009). Tails are thought to be evolved in order to inject DNA efficiently through bacterial cell membrane which is fortified by outer membrane and peptideglycan layer in the case of Gram-negative bacteria or thick peptidoglycan layer containing teichoic acids in the case of Gram-positive bacteria. Bacteriophage which have tails are collectively called Caudovirares consisting of three sub-families, Myoviridae which have a long, contractile tail, Podoviridae which have a short non-contractile tail and Siphoviridae which have long, non-contractile tail. 
Bacteriophage T4 is a Myoviridae which infects Escherichia coli, a Gram-negative bacterium. The virion consists of a head which packages viral genomic DNA, a contractile tail sheath and six tail fibers, LTF, which are the sensor to detect the receptor of the host cell (Figure 1). The head protects the viral DNA from external perturbation including nuclease activity. Tail is an intricate and complex molecular machine which protects DNA from accidental ejection, but also functions as facilitating efficient injection of the DNA in the head into the cytosol of E. coli when it encounters the host. Phage T4 is known to have extremely high efficiency of infection, almost $100 \%$, which means that once the virion recognizes and is adsorbed to the outer membrane, it successfully inject its DNA. Phage adsorption, or receptor recognition, takes place in two steps and the first step is the binding of the tip of LTFs to the glucose residue of the core oligosaccharide LPS (Prehm, 1976). This binding is reversible. The signal of the binding is then transmitted to the baseplate by unknown mechanism, through gp9 (gp: gene product) which is the socket of LTFs and induces the conformational change of the baseplate from "hexgon" to "star" (Crowthe et a., 1977). Six short tail fibers, STF, concomitantly spring out downward and the tip of the STFs now bind to the heptose part of the LPS core oligosaccharide tightly. The conformational change of the baseplate triggers the tail sheath contraction. Recently, the C-terminal domain structure of gp37 which constitutes the distal half fibers has been determined by Bartual et al. (2010), which revealed that gp37 turns back at residue number 950 to form elongated six-stranded anti-parallel beta-strand needle.

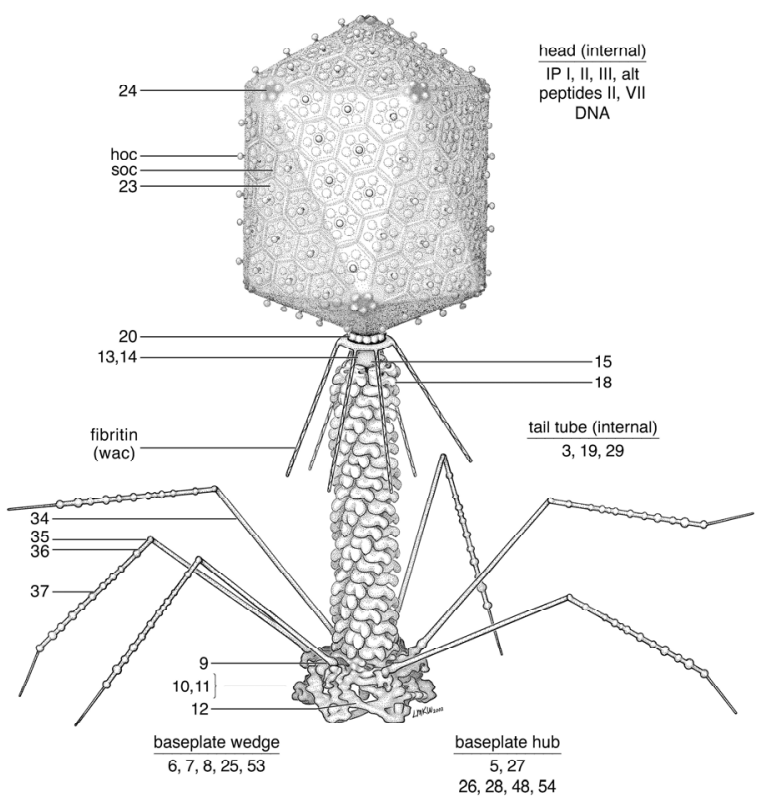

Fig. 1. Bacteriophage T4 (Courtesy of F. E. Eiserling)

Head, tail and six tail fibers are independently assembled. The head first binds a tail and then six tail fibers bind to form a viable phage. For the attachment of the tail fibers to the baseplate through gp9, a baseplate protein, "whisker" protein facilitates the attachment by 
transiently binding tail fibers at the kink position to properly orient the tail fibers. Gp63 also plays a role in facilitating the attachment.

The assembly pathway of the tail of phage T4 has been worked out by a pioneering work by Kikuchi and King (1975a, 1975b, 1975c) (Figure 2). Recently, Yap et al. (2010a) reexamined and confirmed their assembly pathway. Also, they presented experimental results which strongly support the notion that the strictly ordered wedge assembly is based on the conformational change of the subunit proteins upon binding to the precursor complex.

A

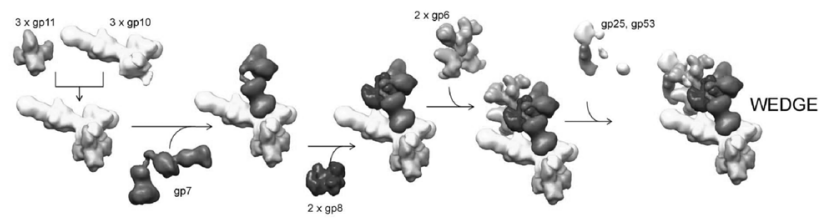

B
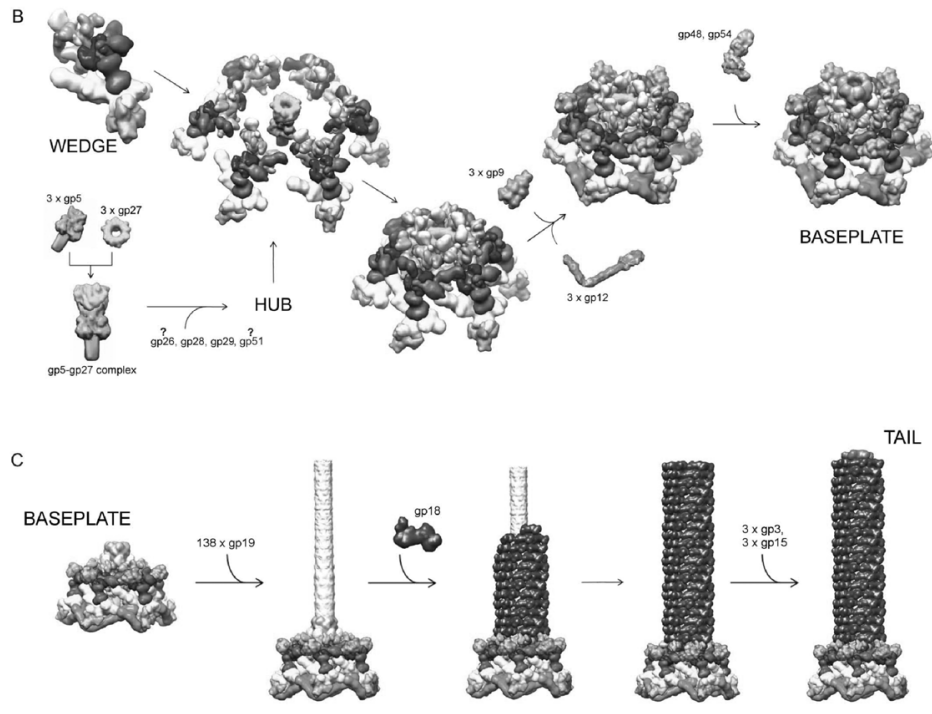

Fig. 2. Assembly of the tail of bacteriophage T4 (P. Leiman et al., 2010)

Structure of the tail in atomic level has been determined by the efforts of Michael G. Rossmann's group at Purdue in collaboration with Vadim V. Mesyanzhinov's, Mark van Raaij's and our group. These results are reviewed by Petr Leiman et al. in the special issue for T4 and T4-related phages of the Virology Journal (Leiman et al., 2010).

Thus, the stoichiometry of most of the tail proteins in phage T4 has been eventually determined by X-ray crystallography, but in this review focus will be made on the methodology of stoichiometry determination in solution before high resolution structures of the components were determined. Also, we would like to emphasize the importance of study of solution interactions. Occasionally, the oligomeric states of subunits are different from what is expected from the X-ray structure (See 3.3 Hub). 


\section{Methodology}

In any interacting systems, stoichiometry and the binding constant are the two most important physical parameters to be determined. If the binding is too tight or irreversible under the normal conditions, the binding constant is difficult to determine, but the stoichiometry is readily determined by measuring the molecular weight of the complex if that of each constituent subunit molecule is known and they are not too different in molecular weight.

\subsection{SDS-PAGE}

Molecular weights of the constituent subunit proteins can be empirically estimated by SDSPAGE. It can be also used to estimate the weight ratio of the constituent proteins, keeping in mind that the intensity of the staining by Coomassie brilliant Blue may depend on the amino acid composition to some extent.

\subsection{Size-exclusion chromatography}

Size exclusion chromatography (SEC, also called gel filtration chromatography) can be used for both analytical and preparative purposes. For molecular weight determination, it takes advantage of the elution volume of the solute which is a linear function of the logarithm of molecular weights. Various gel materials of different pore sizes are available and one could choose the appropriate gels and apply molecular markers. Elution volumes depend on the Stokes radius of the solute and not on the molecular weights. In our research, SEC was therefore only used for preliminary experiments.

\subsection{Analytical ultracentrifugation}

There are two modes in analytical ultracentrifugation; sedimentation velocity (SV) and sedimentation equilibrium (SE). Both SV and SE give absolute molecular weight (Mw) in solution independent of its molecular shape. They also give quantitative information concerning molecular interactions. SV is particularly sensitive in detecting minor components as low as $1 \%$ of the total concentration, but SE is more accurate in determining Mw. If the solute is not homogeneous, SE will give the weight average Mw. Due to the recent advancements particularly in SV analysis, including c(s) analysis (Schuck, 1998), SV has been extensively used in the present study, but when necessary, SE was also carried out. Both SV and SE can deal with quantitative analyses of protein interactions.

Experiments were carried out in Beckman-Coulter Optima XL-I equipped with either 4-hole An60Ti or 8-hole An50Ti rotors at $20^{\circ} \mathrm{C}$. For SV experiments, normal double sector cells were used and $400 \mu \mathrm{l}$ of the sample solution and $430 \mu \mathrm{l}$ of dialysate or equilibrium buffer for SEC were applied in the sample and reference sector, respectively. Dialysate or the buffer solution used for the last step of purification were used as a reference solution in all experiments. All data were acquired without time intervals between successive scans. The sedimentation coefficient distribution function, $\mathrm{c}(\mathrm{s})$, was obtained by using the SEDFIT program (Schuck, 2000). Molecular mass distribution, $c(M)$, was obtained by converting $\mathrm{c}(\mathrm{s})$ into $\mathrm{c}(\mathrm{M})$, on the assumption that the frictional ratio $\mathrm{f} / \mathrm{f}_{0}$ was common to all the molecular species (as implemented in the SEDFIT program). 
For SE experiments, double sector cells or standard six channel centerpieces and quartz windows were used. $110 \mu \mathrm{l}$ of each sample and $120 \mu \mathrm{l}$ of the corresponding dialysate or buffer were loaded. When double sector cells were used, $120 \mu \mathrm{l}$ and $140 \mu \mathrm{l}$ of the sample and reference solutions were loaded. Loading concentrations of the samples as absorbance at 280 $\mathrm{nm}$ were $0.2,0.3$ and 0.5 and the measurements were made at $20^{\circ} \mathrm{C}$. Rotor speeds were decided by using calculator function of SEDFIT. Scans were recorded every $2 \mathrm{~h}$ and the equilibrium of the system was judged by the superimposition of the last three scans. Totally nine datasets were globally fitted to a single species model to determine the weight average molecular weight by non-lin software implemented in the Beckman-Coulter software package. The partial specific volumes based on the amino acid composition of the proteins, the solvent viscosity and solvent density were calculated by Sednterp program (Laue et al., 1992).

\subsection{Electron microscopy}

With regard to stoichiometry, electron microscopy (EM) has been used to identify the symmetry of oligomeric complexes. If some oligomer has a six-fold symmetry, it is likely that the oligomer is hexamer or the multi-mer of 6 as in the case of gp3 and gp15.

Purified sample with approximately $0.1 \mathrm{mg} / \mathrm{ml}$ concentration was loaded on a thin carbon film (supported on top of copper mesh grids) made hydrophilic by glow discharge in a partial vacuum. The sample was washed with five drops of double-distilled water, negatively stained twice with $2 \%$ uranyl acetate solution for $30 \mathrm{~s}$ each time, blotted, and air dried and subjected to observation.

\section{Stoichiometry and protein interactions in the tail of phage T4}

Tail consists of two parts, i.e. a baseplate and a long co-cylinder consisting of a tube and a contractile tail sheath. The baseplate consists of a hub and six wedges surrounding the former. Several other gene products bind to the precursor to complete the baseplate which is then ready to initiate tube and sheath polymerization, which is terminated by gp3 and gp15. Neck made of gp13 and 14 which connects a head and a tail is not a part of the tail, but stoichiometry determination of that part will be included in this section.

\subsection{Wedge}

There are seven gene products in the wedge, i.e. gp11, gp10, gp7, gp8, gp6, gp53 and gp25. The association state and sedimentation coefficient of each gene product are listed in Table 1. Gp11 and gp10 are trimer; gp7 is monomer; gp8 and gp6 are dimer, whereas gp53 and gp25 are monomer in solution. Except for gp11 which can bind to gp10 at any stage of wedge assembly, incorporations of all other gene products are strictly ordered. "Strictly ordered" means that if any of the six gene products is missing, intermediate complex up to that point is formed, but all other gene products that are to be incorporated later will remain unassociated. In order to look at interactions between all the combinations of gene products and assembly pathway, Yap et al. devised a novel method in which each gene was expressed separately in E. coli, cells were mixed and then lysed and the association products were analyzed. The results are listed in Table 2 (Yap et al., 2010b). 
All the interactions in the strictly ordered assembly pathway were confirmed. Sedimentation velocity experiments indicated that there are not very strong, but significant interactions among gp6, gp53, and gp25, which does not comfort to the strictly ordered pathway. Since the interactions were not strong, it was not possible to isolate the complexes by size exclusion chromatography. It is noted that the interaction between gp6 and gp53 was much stronger when gp6 had been associated with the prior wedge intermediate up to gp8. Gp6 in that complex then could not directly bind gp25, but was bound after the binding of gp53. The results strongly suggested that the strict sequential assembly is based on the inducedfit' mechanism, where the binding of each subunit induced a conformational change in the complex to create a binding site for the next subunit entry.

\begin{tabular}{|c|c|c|c|c|c|}
\hline $\begin{array}{l}\text { Gene } \\
\text { product } \\
\text { (gp) }\end{array}$ & $\begin{array}{l}\text { a.a. } \\
\text { residue } \\
\text { number }\end{array}$ & $\begin{array}{l}\text { Stoichiometry } \\
\text { in solution }\end{array}$ & $\begin{array}{l}\text { Stoichiometry } \\
\text { in the tail }\end{array}$ & $\begin{array}{l}\text { Sedimentation } \\
\text { coefficient }\end{array}$ & $\begin{array}{l}\text { Comments, } \\
\text { PDB }\end{array}$ \\
\hline gp11 & 219 & 3 & 18 & $4.2 \mathrm{~S}$ (trimer) & 1EL6 \\
\hline gp10 & 602 & 3 & 18 & 7.8S(trimer) & 2FKK \\
\hline gp7 & 1032 & 1 & 6 & 5.7S(monomer) & \\
\hline gp8 & 334 & 2 & 12 & 5.0S(dimer) & $1 \mathrm{~N} 7 \mathrm{Z}$ \\
\hline gp6 & 660 & 2 & 12 & 6.0S(dimer) & $3 \mathrm{H} 2 \mathrm{~T}$ \\
\hline gp53 & 196 & 1 & 6 & 2.1S(monomer) & \\
\hline gp25 & 132 & 1 & 6 & 1.8S(monomer) & \\
\hline gp5 & 575 & 3 & 3 & ND & $\left.1 \mathrm{~K} 28, \mathrm{SE}^{*}\right)$ \\
\hline gp27 & 391 & 1 & 3 & ND & $1 \mathrm{~K} 28, \mathrm{SE}$ \\
\hline gp29 & 590 & ND & 3 & ND & \\
\hline gp26 & 208 & ND & ND & ND & \\
\hline gp28 & 177 & ND & ND & ND & \\
\hline gp9 & 288 & 3 & 18 & ND & 1S2E \\
\hline gp12 & 527 & 3 & 18 & ND & $\begin{array}{c}\text { 1H6W, } \\
\text { 1OCY, SE }\end{array}$ \\
\hline gp48 & 364 & ND & 6 & ND & \\
\hline gp54 & 320 & ND & 6 & ND & \\
\hline gp18 & 659 & 1 & 138 & 4.2S(monomer) & 3FOA \\
\hline gp19 & 163 & 1 & 138 & ND & \\
\hline gp3 & 176 & 6 & 6 & 7.76S(hexamer) & \\
\hline gp15 & 272 & 6 & 6 & 6.20S(hexamer) & \\
\hline gp57A & 79 & 3 or 6 & - & ND & $\begin{array}{l}\text { molecular } \\
\text { chaperone }\end{array}$ \\
\hline gp51 & 249 & ND & ND & ND & catalytic \\
\hline
\end{tabular}

ND: not determined *) SE: sedimentation equilibrium has been done.

Table 1. Tail proteins and complexes 
Gp10-gp11 complex constitutes the six tail pins at the corners of the dome-shaped baseplate hexagon. Plishker et al. (1988) overexpressed genes 11, 10, 7, and 8, mixed these gene products in various combinations and the formed complexes were then analyzed by native gel electrophoresis. They confirmed the strictly ordered sequential pathway which was proposed by Kikuchi and King (1975), but did not reach the correct stoichiometry.

\begin{tabular}{lcccccc}
\hline Protein/protein complex & gp11 & gp7 & gp8 & gp6 & gp53 & gp25 \\
\hline gp10 & ++ & ++ & - & - & - & - \\
gp7 & - & & - & - & - & - \\
gp8 & - & & & - & - & - \\
gp6 & - & & & & + & + \\
gp53 & - & & & & & + \\
gp10-gp7 & ++ & & ++ & - & - & - \\
gp10-gp7-gp8 & ++ & & & ++ & - & - \\
gp10-gp7-gp8-gp6 & ++ & & & & ++ & - \\
gp10-gp7-gp8-gp6-gp53 & ++ & & & & & ++ \\
\hline
\end{tabular}

++: strong interaction, +: weak interaction, -: no interaction

Table 2. Interactions among wedge proteins

In 2000, Zhao et al. co-expressed gp11 and gp10, isolated the complex and demonstrated by SDS-PAGE, Edman degradation of the complex, and sedimentation equilibrium (SE) that gp10 and gp11 formed a 3:3 stoichiometry complex (Zhao et al., 2000). From the results of Edman degradation and SDS-PAGE, the molar ratio of gp10 and gp11 was determined to be approximately 1 . On the other hand, the molecular weight of the purified gp10-gp11 complex was determined by sedimentation equilibrium to be 284,000 which is close to the expected value of 269,840 , assuming that the stoichiometry is $3: 3$. Furthermore, comparison of the results in the presence and absence of reducing reagent, 2-mercaptoethanol (2-ME), in SDS-PAGE revealed that two molecules of gp10 in the complex formed a disulfide bond, while the third gp10 molecule did not participate in the disulfide bond formation.

Yap et al. (2010a) utilized their novel method to isolate all the possible intermediate complexes with and without gp11, which is an exception due to the fact that gp11 can bind to gp10 at any step of the assembly pathway (2010b). The stoichiometry of intermediate complexes are summarized in Table 3. At present, stoichiometry of gp53 and gp25 is still unkown, although it is clear that they are monomer in solution. Regarding the binding affinities of these association steps of the wedge, their bindings are so tight that once bound they are almost irreversible and the binding constants have not been determined.

Yap et al. also found that when the wedge intermediate $(\mathrm{gp} 10)_{3}(\mathrm{gp} 7)_{1}(\mathrm{gp} 8)_{2}(\mathrm{gp} 6)_{2}$ complex binds gp53, it spontaneously forms a baseplate-like structure in a "star" conformation in the absence of gp25. The biological significance of the baseplate-like structure needs further investigation. 


\subsection{Hub}

The main components of the hub are gp5 and gp27. Gp5 is the "tail lysozyme" which is a structural component of the baseplate and possesses the lysozyme activity. In 1980, it was reported by Kao \& McClain (1980) that the lysozyme activity for the so-called "lysis from without" is gp5. Nakagawa et al (1985) later confirmed the results, isolated gp5 from the tail and identified the lysozyme activity to be $\mathrm{N}$-acetyl muramidase which is the same as that of T4 lysozyme of gp e (gp: gene product). The nucleotide sequence of gene 5 was determined by Mosig et al. (1989).

\begin{tabular}{lll}
\hline Complex & Stoichiometry & \multicolumn{1}{c}{$\mathrm{S}_{20, \mathrm{w}}\left(\mathrm{f} / \mathrm{f}_{0}\right)$} \\
\hline gp10-gp7 & $3: 1$ & $10.2 \mathrm{~S}(1.52)$ \\
gp10-gp7-gp8 & $3: 1: 2$ & $12.1 \mathrm{~S}(1.53)$ \\
gp10-gp7-gp8-gp6 & $3: 1: 2: 2$ & $14.5 \mathrm{~S}(1.64)$ \\
gp10-gp7-gp8-gp6-gp53 & $3: 1: 2: 2: x$ & $15.0 \mathrm{~S}(1.51) ; 43.7 \mathrm{~S}(1.53)$ \\
gp10-gp7-gp8-gp6-gp53-gp25 & $3: 1: 2: 2: x: x$ & $15.3 \mathrm{~S}(1.49) ; 42.0 \mathrm{~S}(1.44)$ \\
gp11-gp10 & $3: 3$ & $9.7 \mathrm{~S}$ \\
gp11-gp10-gp7 & $3: 3: 1$ & $11.9 \mathrm{~S}(1.59)$ \\
gp11-gp10-gp7-gp8 & $3: 3: 1: 2$ & $13.4 \mathrm{~S}(1.56)$ \\
gp11-gp10-gp7-gp8-gp6 & $3: 3: 1: 2: 2$ & $15.3 \mathrm{~S}$ \\
gp11-gp10-gp7-gp8-gp6-gp53 & $3: 3: 1: 2: 2: x$ & $\mathrm{ND}$ \\
gp11-gp10-gp7-gp8-gp6-gp53-gp25 & $3: 3: 1: 2: 2: x: x$ & $16.0 \mathrm{~S}(1.67) ; 40.6 \mathrm{~S}(1.59)$ \\
\hline
\end{tabular}

$\mathrm{x}$ : stoichiometry not determined, $\mathrm{f} / \mathrm{f}_{0}$ : frictional ratio

Table 3. Sedimentation coefficient and frictional ratio of wedge intermediate complex

Kanamaru et al. (1999) have cloned and overexpressed gene 5, and isolated gp5. They proved that it was cleaved at Ser351 and Ala352 during assembly and that the C-terminal domain remained associated to the rest of gp5 until the phage infected the host bacterium. The cleavage between Ser351 and Ala352 gave rise to gp5* and gp5C. Trimeric nature of gp5 in solution was determined by sedimentation equilibrium which revealed that the molecular weight in solution was 194,400 which was close to 189,300 about three times the molecular weight of monomer pre-gp5-his, 63,100, estimated from the amino acid sequence. Trimeric nature of gp27 in the "tail lysozyme complex" was inferred from the interaction study of gp27 and gp5 (Sarkar et al., 2006). The measured molecular weight of gp27-gp5 complex was 319,000 which is close to the expected value of 322,818 , indicating that most of the solute remained as a whole complex, $(\mathrm{gp} 27)_{3}\left(\mathrm{gp} 5^{*}\right)_{3}(\mathrm{gp} 5 \mathrm{C})_{3}$. Measurement of molecular weight at $20^{\circ} \mathrm{C}$, after heat treatment at $37^{\circ} \mathrm{C}$ for half an hour, showed that the complex dissociated into $(\mathrm{gp} 27)_{1}\left(\mathrm{gp} 5^{*}\right)_{1}$ hetero-dimer and $(\mathrm{gp} 5 \mathrm{C})_{3}$ trimer at $\mathrm{pH} 8.6$, but when the $\mathrm{pH}$ was lowered down to 6.0 , the hetero-dimer dissociated into monomers, whereas (gp5C) 3 stayed as a stable trimer. This result was considered relevant to the infection process, as the low $\mathrm{pH}$ in periplasm makes $\mathrm{gp} 5^{*}$ free so that it can cleave peptidoglycan layer to make a local hole through which tail tube can penetrate and reach the inner membrane and probably helps forming a pore in the inner membrane for DNA injection. 
The X-ray crystal structure of the tail lysozyme complex was determined by Kanamaru, Leiman et al. (2001). They confirmed the stoichiometry of (gp27) $)_{3}(\mathrm{gp} 5)_{3}$ and also localized the complex beneath the baseplate by superimposing the high resolution structure into the low resolution electron density of the 3D-reconstituted baseplate from cryo-electron micrographs. Later, Kanamaru et al. (2006) designed a series of mutant gp5 in which amino acid replacements were made at residue 351 to prevent from cleavage. They found that the amino acid replacements caused a various degrees of cleavage suppression. They have crystallized one of the gp5 mutants, S351L, in complex with gp27, and determined the structure around the cleavage site, which was not possible in the previous study. Interestingly, the mutant phage did not lose the phenotype although it showed some cold sensitive phenotype.

The localization and stoichiometry of gp29, which is the ruler molecule (Abuladze et al., 1994), has not been worked out yet. Gp29 has been difficult to isolate. It is assumed that it first forms a spherical-shape oligomeric complex, binding to the upper central part of the hub. The current model states that, as the tail tube polymerizes, it elongates itself and when it is completely extended, gp3 binds to the tip of gp29 and gp19, the tube protein to stop the polymerization. The tail length determination is the first system where the mechanism was explained by the ruler molecule or tape measure protein.

Neither the localization nor the number of molecules of gp26 and gp28 per a baseplate has been determined. It has been reported that when gene 27 is expressed together with gp28, gp27 is found in the membrane fraction (Nieradko and Koszalka, 1999). Gp51, which is essential for the assembly of the baseplate, has been reported to function catalytically, but how gp51 works as a catalyst is not known (Snustad, 1968).

Kikuchi \& King's model (1975a) stated that 6 wedges surrounded a hub to form a baseplate intermediate complex. On the other hand, Yap et al. (2010a) found that upon binding of gp53 to the intermediate complex, a baseplate-like structure in a "star" conformation took place. The significance of this observation has to wait for further study, but the observation should be related to the association property of the wedge complex.

KVP40 is a T4-related vibrio phage which has a broad host range. Nemoto et al. (2008) have cloned, overexpressed, purified, and biophysically characterized two proteins encoded in the KVP40 genome, namely, gp5 and ORF334. Homology-based comparison between KVP40 and phage T4, was used to estimate the two KVP40 proteins functions. KVP40 gp5 shared significant homology with T4 gp5 in the N- and C-terminal domains, but lacked the internal lysozyme domain. Like T4 gp5, KVP40 gp5 was found to form a homotrimer in solution. In contrast, KVP40 ORF334 shared no significant homology with any known proteins from T4-related phages. KVP40 ORF334 was found to form a heterohexamer with KVP40 gp5 in solution in a fashion nearly identical to the interaction between the T4 gp5 and gp27 proteins. Electron microscope image analysis of the KVP40 gp5-ORF334 complex indicated that it had a very similar size to the T4 gp5-gp27 structure. On the basis of biophysical characterization, along with positional genome information, ORF334 was concluded to be the ortholog of T4 gp27, playing the role of a linker between gp5 and the phage baseplate. 


\subsection{Other baseplate proteins}

After the baseplate precursor structure is formed, gp9, which is the socket molecule for the long tail fibers, binds to the upper six corners of the baseplate, and gp12, which constitutes the short tail fibers, binds beneath the baseplate. Gp9 is the first among tail proteins whose crystal structure was determined by X-ray crystallography (Kostychenko et al., 1999). Gp9 is a trimer both in solution and in the baseplate, showing two domains which are connected by a flexible linker. This linker makes it possible for the tail fiber to assume two different orientations. The N-terminal domain of gp9 which binds the tail fibers tightly can point to a direction away from the tail sheath, but at lower $\mathrm{pH}$, they take retracted configuration or bind along the tail sheath. Gp12 is also a trimeric protein. It is a trimer in solution at $37{ }^{\circ} \mathrm{C}$, but the trimer reversibly associates into 18-mer (trimer $\times 6$ ) at $20^{\circ} \mathrm{C}$, based on sedimentation equilibrium (Yamazaki \& Arisaka, unpublished results). Hexamerization of the trimer is strongly dependent on the salt concentration and in the presence of $1 \mathrm{M} \mathrm{KCl}, \mathrm{gp} 12$ is trimeric $20^{\circ} \mathrm{C}$. In retrospect, the hexamer might have been the "garland" as Kostychenco et al. have called it (Kostychenko et al., 2003), where trimeric gp12 form an outer most ring of the baseplate. Under the baseplate, the N-terminal gp12 tightly binds to the domain IV of gp10 and the C-terminal gp12 binds to the N-terminal domain of the neighboring trimeric gp12. When the baseplate changes its conformation from "hexagon" to "star", the C-terminus of gp12 detaches from the N-terminus of the neighbouring gp12 and springs out downward and tightly binds to the heptose part of LPS.

Following gp9 and gp12 binding to the baseplate, gp48 and gp54 bind to the upper center part of the baseplate in this order to complete the baseplate formation and now ready for tail tube, gp19, polymerization (Berget and Warner, 1975). The stoichiometry of gp48 and gp54 in solution is not known, but six molecules each are present in the baseplate.

\subsection{Phage-encoded molecular chaperone, gp57A}

Folding of short tail fibers requires the presence of phage-encoded molecular chaperone, gp57A. Gp57A is also required for the folding of proximal and distal half fibers, gp34 and gp37. Analytical ultracentrifugation (AUC), differential scanning microcalorimetry (DSC), and stopped-flow circular dichroism (CD) were used to establish the association scheme of gp57A (Ali et al., 2003). It is an oligomeric $\alpha$-helix protein with 79 amino acids. Analysis of the sedimentation velocity data by direct boundary modelling with Lamm equation solutions together with a more detailed boundary analysis incorporating association schemes, led us to conclude that at least three oligomeric species of gp57A are in reversible and fast association equilibrium, and that a 3 mer-6mer- 12 mer model describes the data best. On the other hand, DSC revealed a highly reversible two-step transition of dissociation/denaturation, both of which were accompanied by a decrease in CD at $222 \mathrm{~nm}$. The melting curve analysis revealed that it is consistent with a 6 mer-3mer- 1 mer model. The refolding/association kinetics of gp57A, measured by stopped-flow $\mathrm{CD}$, was consistent with the interpretation that the bimolecular reaction from trimer to hexamer is preceded by a fast $\alpha$-helix formation in the dead-time. Trimer or hexamer is likely the functional oligomeric state of gp57A. 


\subsection{Tail tube and sheath}

The 138 subunits of both tail tube, gp19, and sheath, gp18, assemble on the baseplate to form 23 hexameric rings which are terminated by gp3 and gp15, respectively (Zhao et al., 2003). The number of the rings were determined by 3D-image reconstruction of the tail from electron micrographs (Kostychenko et al., 2005). Previously, the number of rings were reported to be 24 (Amos and Klug, 1975), but that was due to the difficulty of counting rings at the baseplate attachment site with the available resolution at that time. Higher resolution of the recent studies made it clear that the number is 23 . X-ray crystal structure of Cterminal deleted mutant gp18M (1-510 a.a.res.) has been solved by Aksyuk et al. (2009) to 3.5 A resolution. The high resolution structure and the fold of gp18 confirmed our previous results that the protease-resistant domain is between residue 82 and 316 and that the Cterminus is close to the N-terminus based on both chemical modification and mutation analysis (Takeda et al., 1990; Arisaka et al. 1990;Takeda et al., 2004).

Tube and sheath make identical helices and each gp19 tube subunit spatially corresponds to gp18 sheath subunit. Each ring is $40.6 \mathrm{~A}$ and is rotated by $17.2^{\circ}$ in a right-handed manner relative to the previous ring. The sheath surrounds the tail tube and the tube has the same helical parameter as the tail sheath. Tails can be isolated from head- mutant (23-) infected cells. When the isolated tails are exposed to low ionic strength buffer, the tail sheath are readily dissociated from the tube-baseplate complex into monomers. If the monomeric sheath protein is mixed with the tube-baseplate and $0.1 \mathrm{M} \mathrm{KCl}$ is added, the monomeric protein self-assembles onto the tube-baseplate to form the extended tail sheath. The sheath assembly is very cooperative; in the reassembled solution, only complete sheath and tubebaseplates are present and incomplete sheath are rarely seen under electron microscopy of negatively stained specimens. Sedimentation velocity experiment confirmed the cooperativity, where only tube-baseplate, 70S, and the complete tail, 120S, are observed (Arisaka et al., 1979). The sheath is not dissociated once the head is attached, but the stabilization mechanism is not known. The whisker, gpwac, is not responsible for the stabilization, because wac- phage has a stable sheath.

\section{Neck proteins, gp13 and gp14}

Once packaging of DNA into the head of bacteriophage T4 is completed, a neck is formed at the portal vertex of the head to be ready for the tail attachment. The main components of the neck are gp13 and gp14, which consist of 309 and 256 amino acid residues, respectively. In order to elucidate the structure and subunit arrangement in the neck, overexpression systems of gene 13 and gene 14 were constructed and purified to homogeneity (Akhter, T., 2007). Far-UV circular dichroism (CD) spectra of gp13 and gp14 indicated that gp13 is rich in a-helices whereas gp14 is rich in $\beta$-sheets. Sedimentation velocity analysis of gp13 and gp14 revealed that both proteins are present as monomers in solution. The frictional ratios ( $\mathrm{f}$ $/ \mathrm{f}_{0}$ ) of the two proteins indicated that gp14 has a more elongated shape than gp13. Although isolated gp13 and gp14 do not interact with each other when mixed under physiological conditions, they form a hetero-oligomer complex with the stoichiometry of 10:5 after treatment with ammonium sulfate. Electron microscopy of this complex has shown that it forms a ring-like structure of $15 \mathrm{~nm}$ in diameter. 


\section{Conclusions and perspectives}

Investigations on the assembly of bacteriophage have been facilitated by the isolation of conditional lethal mutants such as temperature sensitive and amber mutants in the early 1960s (Epstein et al., 1964). The former mutants can grow at $30^{\circ} \mathrm{C}$, but not $42^{\circ} \mathrm{C}$. The latter cannot grow on the wild type E. coli, but grow on the amber suppressor strains of E. coli. The phenotype of amber mutants can be examined by using wild type bacterium as a host and when necessary the mutants can grow on the permissive strains. The assembly pathway of the phage has been investigated by sucrose density gradient, SDG, of the lysate in combination with in vitro complementation (Kikuchi \& King, 1975a, b, c; Coombs \& Arisaka).

A number of head proteins such as the major capsid protein, gp23, and minor capsid protein, gp24, undergo processing and lose 65 and about 20 residues, respectively, before DNA packaging, but no tail proteins except for gp5, tail lysozyme, are cleaved during assembly.

Assembly of the wedge part is strictly ordered, which means that in the absence of a particular gene product, gene products up to that point form an intermediate and the other gene products stay free in the cytosol. Assembly of other parts of the phage are not so strict, but also ordered to various degrees. Ordered assembly pathway is common to all the viral assembly and necessary presumably to avoid undesired interaction of the incomplete parts for the ultimate complete assembly of virion which is viable. The ordered assembly of the wedge was originally demonstrated by Kikuchi and King in 1975,, and it was later confirmed by in vivo pulse-chase analysis by Ferguson and Coombs (2000) and by recent solution study by Yap et al. (2010). Meanwhile, high resolution structures of many of the gene products have been determined, which was recently reviewed by Petr Leiman et al. (2010).

There are totally 22 genes which are essential for the formation of the tail. Among them, gp57A is a phage-encoded molecular chaperone for long and short tail fibers and gp51 is known to function catalytically. Neither of them are present in the final virion. Amon the 20 gene products which constitutes parts of the virion, complete structure of gp11, gp8, gp5, gp27, gp9, and partial structures gp10, gp6, gp12, gp18 have been determined by X-ray crystallography. Structures of the remaining ten gene products, gp7, gp53, gp25, gp29, gp26, gp28, gp48, gp54, gp19, gp3 and gp15 remain to be determined.

The final product of the assembly, a bacteriophage virion, is a robust and stable structure. On the other hand, some of the intermediate structures during assembly are unstable and easily dissociable. These reversible interactions are facilitated and stabilized by irreversible interactions in the later stages. For example, tail sheath protein interactions involved in forming the extended sheath are relatively weak, but stabilized when the head is attached to the tail.

How the phage-encoded molecular chaperone, gp57A, functions is not known. The hypothesis that the ruler molecule or tape measure protein, gp29, determines the length of the tail by stopping the polymerization of the tail tube protein upon full extension of the originally spherical molecule has not been proved. 
Further structure determination of the tail proteins and study on their interactions are necessary for the full understanding of the mechanism of assembly and infection.

\section{Acknowledgment}

The author would like to give sincere thanks to M. G. Rossmann and V. V. Mesyanzhinov and our collaborators, especially S. Kanamaru, P. Leiman, and V. Kostychenko, for their long-standing collaboration. This study was supported by a Human Frontier Science Program_HFSP_to Michael G. Rossmann, Vadim V. Mesyanzhinov, and F.A.; Grant-in-Aid for Scientific Research on Priority _B_ from the Ministry of Education, Culture, Sports, Science and Technology; and Grant-in-Aid for Scientific Research _C_ from Japan Society for the Promotion of Science to F. A.

\section{References}

Abuladze, N.K., Gingery, M., Tsai, J. and Eiserling, F.A. (1994) Tail length determination in bacteriophage T4. Virology Vol. 199, pp. 301-310

Ackerman, H.-W. (2009). Phage classification and characterization. Methods Mol.Bio., Vol.510, pp.127-140

Akhter T., Zhao L., Kohda A., Mio K., Kanamaru S., Arisaka F. (2007) The neck of bacteriophage T4 is a ring-like structure formed by a hetero-oligomer of gp13 and gp14 Biochim Biophys Acta. 1774(8):1036-43

Aksyuk A. A., Leiman P. G., Kurochkina L. P., Shneider M. M., Kostyuchenko V.A., Mesyanzhinov V. V., Rossmann M. G. (2009) The tail sheath structure of bacteriophage T4: a molecular machine for infecting bacteria. EMBO J. Vol. 28, pp.821-829.

Ali S.A., Iwabuchi N., Matsui T., Hirota K., Kidokoro S.-I., Arai M., Kuwajima K., Schuck P., and Arisaka F. (2003) Reversible and Fast Association Equilibria of a Molecular Chaperone, gp57A, of Bacteriophage T4, Biophys. J. Vol.85, pp.1-13

Amos, L. A. and Klug, A. (1975) Three-dimensional image reconstruction of the contractile tail of the T4 bacteriophage, J. Mol. Biol. Vol.99, pp.51-73

Arisaka F., Takeda S., Funane K., and Ishii, S.-I. (1990) Structural Studies of the Contractile Tail Sheath Protein of Bacteriophage T4 II. Structural Analyses of the Tail Sheath Protein, gp18, by Limited Proteolysis, Immunoblotting and Immuno-electron Microscopy. Biochemistry 29:5057-5062

Arisaka, F., Tschopp, J., van Driel, R., and Engel, J. (1979) Reassembly of the Bacteriophage T4 Tail from the Core-Baseplate and the Monomeric Sheath Protein P18: A Cooperative Association Process, J. Mol. Biol. Vol. 132, pp. 369-386

Bartual, S.G., Otero J.M., Garcia-Doval C., Llamas-Saiz A.L., Kahn R., Fox GC, van Raaij MJ.(2010) Structure of the bacteriophage T4 long tail fiber receptor-binding tip, Proc Natl Acad Sci U S A. Vol.107 No.4,pp.20287-92

Berget, P. B., and Warner, H. R. (1975) Identification of P48 and P54 as components of bacteriophage T4 baseplate, J. Virol. Vol.16, pp.1669-1677

Coombs, D.H., Arisaka, F. (1994) T4 Tail Morphogenesis, in "Molecular Biology of Bacteriophage T4" (ed. by Jim Karam), pp.259-281 American Society for Microbiology, Washinton, DC 
Crowther, R.A., Lenk, E.V., Kikuchi, Y., and King, J. (1977) Molecular reorganization in the hexagon to star transition of the baseplate of bacteriophage T4. J. Mol. Biol. Vol. 116, pp.489-523

Epstein, R. H., Bolle, A., Steinberg, C., Kellenberger, E., Boy de la Tour, E., Chevalley, R., Edgar, R., Susman, M., Denhart, C., and Lielausis, I. (1964) Physiological studies of conditional lethal mutants of bacteriophage T4D. Cold Spring Harbor Symp. Quant. Biol. Vol.28, pp.375-392

Ferguson PL, Coombs DH. (2000) Pulse-chase analysis of the in vivo assembly of the bacteriophage T4 tail. J Mol Biol. 297(1):99-117.

Fraenkel-Conrat, H., and Williams, R. C. (1955) Proc Natl Acad Sci U S A. Vol. 41, pp. 690 698

Kanamaru, S., Gassner, N. C., Ye, N., Takeda, S., and Arisaka, F. (1999)The C-Terminal Fragment of the Precursor Tail Lysozyme of Bacteriophage T4 Stays as a Structural Component of the Baseplate after Cleavage J. Bacteriol. Vol. 181, No. 9, pp.27392744

Kanamaru S., Leiman P. G., Kostychenco V. A., Chipman P. R., Mesyanzhinov V. V., Arisaka, F., and Rossmann, M.G. (2002) Structure of the cell-puncturing device of bacteriophage T4. Nature Vol. 415, pp. 553-557

Kanamaru, S., Ishiwata, Y., Suzuki, T. Rossmann, M. G., Arisaka, F. (2005) Control of Bacteriophage T4 Tail Lysozyme Activity During the Infection Process J. Mol. Biol. Vol. 346, pp.1013-1020

Kao, S. H. and W.H. McClain, W. H. (1980) Baseplate protein of bacteriophage T4 with both structural and lytic functions. J. Virol. Vol. 34, pp95-103

Kikuchi, Y. and King, J. (1975) Genetic control of bacteriophage T4 baseplate morphogenesis I. Sequential assembly of the major precursor, in vivo and in vitro. J. Mol. Biol. 99: 645-672

Kikuchi, Y. and King, J. (1975) Genetic control of bacteriophage T4 baseplate morphogenesis II. Mutants unable to form the central part of the baseplate. $J$. Mol. Biol. 99:673-694

Kikuchi, Y. and King, J. (1975) Genetic control of bacteriophage T4 baseplate morphogenesis III. J. Mol. Biol. 99:695-716

King, J. (1968) Assembly of the tail of bacteriophage T4, J. Mol. Biol. Vol. 32, pp.231262

Kostyuchenko, V. A., Navruzbekov, G. A., Kurochkina, L. P., Strelkov, S. V., Mesyanzhinov, V. V., and Rossmann, M. G. (1999) The structure of bacteriophage T4 gene product 9: the trigger for tail contraction. Structure Fold Des.Vol. 7, pp.1213-1222

Kostychenko V.A., Leiman P.G., Chipman, P.R., Kanamaru, S., van Raaij, M.J., and Arisaka, F., Mesyanzhinov, V.V., Rossmann, M.G. (2003) Three-dimensional structure of bacteriophage T4 baseplate. Nat. Struct. Biol. Vol.10, pp.688-693

Kostyuchenko V.A., Chipman P.R., Leiman P.G., Arisaka F., Mesyanzhinov, V.V. Rossmann M.G. (2005) The tail structure of bacteriophage T4 and its mechanism of contraction. Nat Struct Mol Biol. Vol.12, pp.810-813 
Laue, T. M., Shah, B.D., T. M. Ridgeway, T. M., and S. L. Pelletier, S. L., (1992) Computeraided interpretation of analytical sedimentation data for proteins, p.90-125. In S. E. Harding, A. J. Rowe, and J. C. Horton (ed.), Analytical ultracentrifugation in biochemistry and polymer science. Royal Society of Chemistry, Cambridge, United Kingdom.

Leiman, P., Fumio Arisaka, Mark J. van Raaij, Victor A. Kostychenko, Anastasia A. Aksyuk, Shuji Kanamaru, Michel G. Rossmann (2010) Virology J. Vol. 7, pp.355-382

Mosig, G., Lin, G. W., Franklin, J., and Fan, W. H. Functional relationship and structural determination of two bacteriophageT4 lysozymes: a soluble (gene e) and a baseplate-associated (gene 5) protein. New Biol. 1:171-179 (1989)

Nemoto M., Mio K., Kanamaru S., Arisaka F.: ORF334 in Vibrio phage KVP40 plays the role of gp27 in T4 phage to form a hetero-hexameric complex. J. Bacteriol. 190(10): 3606$3612(2008)$

Nakagawa, H., Arisaka, F., and Ishii, S.-I. (1985) Isolation and characterization of the bacteriophage T4 tail-associated lysozyme. J. Virol. Vol. 54, pp.460-466

Nieradko, J. and Koszałka, P. (1999) Evidence of interactions between gp27 and gp28 constitutes the central part of bacteriophage T4 baseplate. Acta Microbiol. Pol. Vol. 48 , pp. 233-242

Plishker, M. F. , Rangwala, S. H., Berget, P. B. (1988) Isolation of bacteriophage T4 baseplate protein P7 and P8 and in vitro formation of the P10/P7/P8 assembly imtermediate. J. Virol. Vol. 62, No. 2, pp. 400-406.

Prehm, P., Jann, B., Jann, K., Schmidt, G., and Stirm, S. (1976) On a bacteriophage T3 and T4 receptor region within the cell wall lipopolysacchride of E.coli B. J. Mol. Biol. Vol. 101, pp.277-281

Sarkar, S. K., Takeda, Y., Kanamaru, S., Arisaka, F. (2006) Association and dissociation of the cell puncturing complex of bacteriophage $\mathrm{T} 4$ is controlled by both $\mathrm{pH}$ and temperature Biochim. Biophys. Acta Vol.1764, pp.1487-1492

Schuck, P. (1998) Sedimentation analysis of noninteracting and self-associating solutes using numerical solutions to the Lamm equation. Biophys. J. Vol. 75, pp.1503-1512

Schuck P. (2000) Size distribution analysis of macromolecules by sedimentation velocity ultracentrifugation and Lamm equation modeling. Biophys. J. 78:1606-1619.

Snustad, D. P. (1968) Dominance interactions in Escherichia coli cells mixedly infected with T4D wild-type and amber mutants and their possible implications as to type of gene-product function: catalytic vs. Stoichiometric. Virology Vol. 35, pp.550-563

Takeda S., Arisaka F., Ishii S.-I., and Kyogoku Y. (1990) Structural Studies of the Contractile Tail Sheath Protein of Bacteriophage T4 I. A Conformational Change of the Tail Sheath Upon Contraction As Probed by Differential Chemical Modification. Biochemistry 29:5050-5056

Takeda S., Suzuki M., Yamada T., Kageyama M., and Arisaka F. (2004) Mapping of functional sites on the primary structure of the contractile tail sheath protein of bacteriophage T4 by mutation analysis. Biochim. Biophys. Acta 1699(1-2): 163-171

Yap, M.L., Mio, K., Leiman, P.G., Kanamaru, S., and Arisaka, F. (2010a) The Baseplate Wedges of Bacteriophage T4 Spontaneously Assemble into Hubless Baseplate-like Structure In Vitro. J. Mol. Biol. 395:349-360 
Yap, M. L., Mio, K., Ali, S., Minton, A., Kanamaru, S., Arisaka, F. (2010b) Sequential Assembly of the Wedge of the Baseplate of Phage T4 in the Presence and Absence of gp11 as Monitored by Analytical Ultracentrifugation. Macromol. Biosci. Vol. 10, pp. $808-813$

Zhao L., Takeda S., Leiman, P. G., Arisaka F. (2000) Stoichiometry and inter-subunit interaction of the wedge initiation complex, gp10-gp11, of bacteriophage T4. Biochim. Biophys. Acta. Vol.1479, No.1-2, pp.286-92.

Zhao L., Kanamaru S., Chaidirek C., Arisaka F. (2003) P15 and P3, the Tail Completion Proteins of Bacteriophage T4, Both Form Hexameric Rings, J. Bacteriol. Vol. 185, pp. 1693-1700 (2003) 


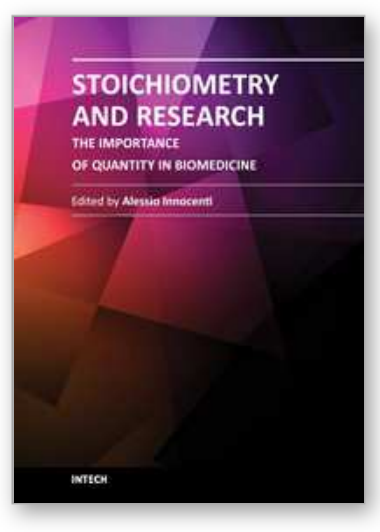

\section{Stoichiometry and Research - The Importance of Quantity in Biomedicine}

Edited by Dr Alessio Innocenti

ISBN 978-953-51-0198-7

Hard cover, 376 pages

Publisher InTech

Published online 07, March, 2012

Published in print edition March, 2012

The aim of this book is to provide an overview of the importance of stoichiometry in the biomedical field. It proposes a collection of selected research articles and reviews which provide up-to-date information related to stoichiometry at various levels. The first section deals with host-guest chemistry, focusing on selected calixarenes, cyclodextrins and crown ethers derivatives. In the second and third sections the book presents some issues concerning stoichiometry of metal complexes and lipids and polymers architecture. The fourth section aims to clarify the role of stoichiometry in the determination of protein interactions, while in the fifth section some selected experimental techniques applied to specific systems are introduced. The last section of the book is an attempt at showing some interesting connections between biomedicine and the environment, introducing the concept of biological stoichiometry. On this basis, the present volume would definitely be an ideal source of scientific information to researchers and scientists involved in biomedicine, biochemistry and other areas involving stoichiometry evaluation.

\section{How to reference}

In order to correctly reference this scholarly work, feel free to copy and paste the following:

Fumio Arisaka (2012). Stoichiometry of Protein Interactions in Bacteriophage Tail Assembly, Stoichiometry and Research - The Importance of Quantity in Biomedicine, Dr Alessio Innocenti (Ed.), ISBN: 978-953-51-0198-7, InTech, Available from: http://www.intechopen.com/books/stoichiometry-and-research-the-importance-ofquantity-in-biomedicine/stoichiometry-of-protein-interactions-in-bacteriopahge-assembly

\section{INTECH}

open science | open minds

\section{InTech Europe}

University Campus STeP Ri

Slavka Krautzeka 83/A

51000 Rijeka, Croatia

Phone: +385 (51) 770447

Fax: +385 (51) 686166

www.intechopen.com

\section{InTech China}

Unit 405, Office Block, Hotel Equatorial Shanghai

No.65, Yan An Road (West), Shanghai, 200040, China

中国上海市延安西路65号上海国际贵都大饭店办公楼 405 单元

Phone: +86-21-62489820

Fax: $+86-21-62489821$ 
(C) 2012 The Author(s). Licensee IntechOpen. This is an open access article distributed under the terms of the Creative Commons Attribution 3.0 License, which permits unrestricted use, distribution, and reproduction in any medium, provided the original work is properly cited. 